\title{
Evaluation of cover soil properties of solid waste dumpsites in Colombo District, Sri Lanka
}

\author{
H.M.D. Harshani ${ }^{1}$, Udeni P. Nawagamuwa ${ }^{1^{*}}$ and Asitha Senanayake ${ }^{2}$ \\ ${ }^{1}$ Department of Civil Engineering, Faculty of Engineering, University of Moratuwa, Moratuwa. \\ ${ }^{2}$ Department of Civil Engineering, The University of Texas at Austin, Austin, TX 78712, USA.
}

Revised: 24 November 2014; Accepted: 25 March 2015

\begin{abstract}
Landfill cover soils have to serve multiple purposes such as operational safety, environmental protection, recultivation and integration of the sites into the landscape. Cover soil properties must therefore be defined with respect to the thickness, bulk density, air permeability and the available field capacity. The primary objective of this study is to examine the cover soil properties of three selected landfill sites (dumpsites) in Sri Lanka in order to propose suitable cover soil properties for similar applications in future dumpsites. Soil samples were obtained from three landfill sites in and around the city of Colombo. Laboratory tests to establish compaction characteristics, air permeability, particle size distribution and Atterberg limits were performed to assess the suitability as landfill cover soils. The study showed that landfill covers with well graded soils comply with the dry density and air permeability values, as per the guidelines. In the absence of proper gas venting facilities, it is essential to study the permeability properties of the cover soil. All three landfill sites tested need to be retrofitted with leachate and gas collecting systems that meet the standards stipulated in the guidelines.
\end{abstract}

Keywords: Air permeability, compaction, cover soil, landfill.

\section{INTRODUCTION}

Landfills is the preferred method of waste disposal in Sri Lanka and many other parts of the world including most notably, North America. They can be classified as sanitary landfills, engineered landfills, controlled landfills and uncontrolled landfills (open dumping). Due to numerous biochemical reactions occurring within the waste body these landfills produce biogas and leachates, which contribute to the pollution of air, water and soil. The leachate production can be reduced by increasing the storage capacity of the cover soil as it reduces percolation into the underlying waste. Therefore, the landfill covers must be designed in order to minimize percolation through the cover and gas migration to the atmosphere.

In Sri Lanka, the primary waste dumping method is the open dumping, which is uncontrolled and only a very few controlled waste disposal sites are available (Visvanathan et al., 2005). Even in the controlled landfills, there are many problems such as the release of hazardous gases to the atmosphere and the groundwater pollution. The lack of technical knowledge and insufficient maintenance are the main reasons for such problems. Retrofitting of the existing landfills has to be done to reduce future groundwater contamination potential. This can be done by introducing a base leachate collection system or leachate extraction wells within the landfill.

In general, the main functions of a landfill cover soil include the prevention of greenhouse gas emissions and the minimizing of the leachate production. The cover soil properties such as the bulk density, soil thickness and air capacity, which minimize leachate production may conflict with the physical properties necessary to deplete greenhouse gas emissions. Waste disposal sites, which have good gas exchangeable properties may not minimize percolation. If a low gas exchangeable soil is used in order to reduce percolation, a separate ventilation method should be provided. For optimization of the requirements on both functions, it is better to have proper guidelines for selecting a suitable cover soil. Soil compaction also has a major impact on gas transport characteristics. Generally, the landfill final cover soils are highly compacted to prevent precipitation infiltration. Weeks et al. (1992) have reported that the

*Corresponding author (udeni@uom.lk) 
bulk density could be in the range of $1.57-1.74 \mathrm{~g} \mathrm{~cm}^{-3}$ for differently-textured landfill cover soils. Further in the same study, the field investigation has shown that the in situ bulk density reached $1.90 \mathrm{~g} \mathrm{~cm}^{-3}$. Ranasinghe et al. (2010) showed that gas transport parameters of cover soil in the Maharagama landfill are very low due to heavy compaction.

Soil air permeability of the final cover soil is extremely important to reduce the gas flow into the atmosphere. If the cover system is not properly designed, the gas will escape to the atmosphere without any control. The Darcy's law can be formulated for the flow of a viscous and incompressible fluid within a porous medium under laminar conditions. The volumetric flow (Q) of a gas in porous media can be described by the following expression:

$$
Q=\frac{(K a \times \Delta P \times A)}{\eta}
$$

where $Q$ is the volumetric flow rate and $\Delta P$ is the pressure difference between the injected air and the atmospheric pressure. " $A$ " represents a shape factor, $K a$ is the air permeability of soil and $\eta$ is the dynamic gas viscosity.

Several studies have been carried out to improve or find out alternate methods to reduce groundwater pollution from leachates and prevent methane emission from the cover. Winkler (1999) proposed a monolithic landfill cover, which minimizes the infiltration by maximizing the storage capacity. Studies on evapotranspiration (ET) covers, which utilizes the water uptake capabilities of vegetation and the storage capacity of fine-grained soils to reduce percolation into the underlying waste (Abichou et al., 2003) have highlighted that cover thickness, air capacity and water retention capacity of the cover material are the important aspects that have to be considered for designing an ET cover. This type of ET cover requires much less maintenance and most of it deals with vegetation, which is relatively easy to maintain. Hence, the climate, soil type and suitable vegetation type of each site should be investigated.

The objective of this research was to study the present condition of the cover soils in the open dumps in Sri Lanka, and to propose suitable cover materials for the newly proposed dumping sites.

\section{METHODS AND MATERIALS}

Disturbed soil samples were collected from the open dumpsites at Karadiyana, Sedawaththa and
Kelaniya. Using the samples a sieve analysis, Proctor compaction, Atterberg limit and air permeability tests were carried out. Test results related to the Maharagama landfill site by Ranasinghe et al. (2010) were also used for comparison purposes.

Sieve analysis tests were performed as per the standard test method given in ASTM D 422 - 63 (ASTM, 1998). Standard Proctor compaction tests were conducted according to ASTM D 698 (ASTM, 2012). To determine the liquid limit and plastic limit, the samples were prepared and tested in Casagrande apparatus according to ASTM D 4318 (ASTM, 2010).

The transport of gases in soil is basically controlled by advection and convection in the air-filled pore spaces where the gases can move freely through the soil. Air permeability of soil $\left(K_{a}\right)$ governs the convective transmission of air through soil under an applied total pressure gradient. The theory for the flow of air through soil is based on Darcy's law, which states that the velocity of a fluid flowing through a porous column is directly proportional to the pressure difference, and inversely proportional to the length of the column.

$K_{a}$ can be calculated if the rate of flow of air through a porous sample of known dimensions under a known pressure difference is measured. The tests were performed using a specimen with a diameter of $50 \mathrm{~mm}$ and a height of $50 \mathrm{~mm}$. The dynamic gas viscosity was around $1.98 \mathrm{e}-5 \mathrm{~kg} / \mathrm{ms}$. To calculate the shape factor the following equation proposed by Liang et al. (1995) was used.

$$
A=D\left\{0.4862\left(\frac{D}{H}\right)-0.0287\left(\frac{D}{H}\right)^{2}\right\}+0.1106
$$

where $D$ is the diameter of the soil sample and $H$ represents the inserted depth of the core cutter.

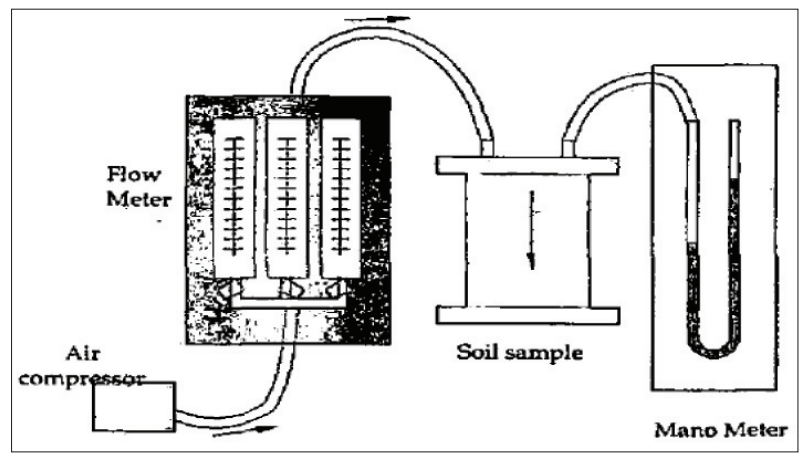

Figure 1: Schematic diagram of air permeability measuring apparatus (Ranasinghe et al., 2010) 
Air permeability was measured for three moisture levels for each sample. Moisture levels are approximate values of minimum moisture content, optimum moisture content and maximum moisture content selected from the Proctor compaction test results.

$K_{a}$ was measured for each disturbed soil sample in the laboratory using the modified field air permeameter proposed by Iversen et al. (2001). The schematic diagram describing the apparatus is shown in Figure 1.

\section{RESULTS AND DISCUSSION}

The results of each test was summarized in order to compare the soil properties in different soil covers. Figure 2 shows the grading curve for each soil sample taken from the sieve analysis test results. As shown in Figure 2, the percentage passing through no. 200 sieve (fine content) of the Maharagama site had the maximum value of $21 \%$ (Ranasinghe et al., 2010) while the Karadiyana site had $10 \%$ and the other two places had very low values such as 2.8 and $3.8 \%$.

The optimum moisture content and the maximum dry density were determined from the Proctor compaction curves presented in Figure 3. The Maharagama and the Karadiyana sites showed a maximum dry density of more than $1900 \mathrm{~kg} / \mathrm{m}^{3}$ at around $14 \%$ optimum moisture content, while the other two sites showed lower dry density, even less than $1600 \mathrm{~kg} / \mathrm{m}^{3}$.

The plasticity index was calculated using the liquid limit and the plastic limit of each soil and the results have

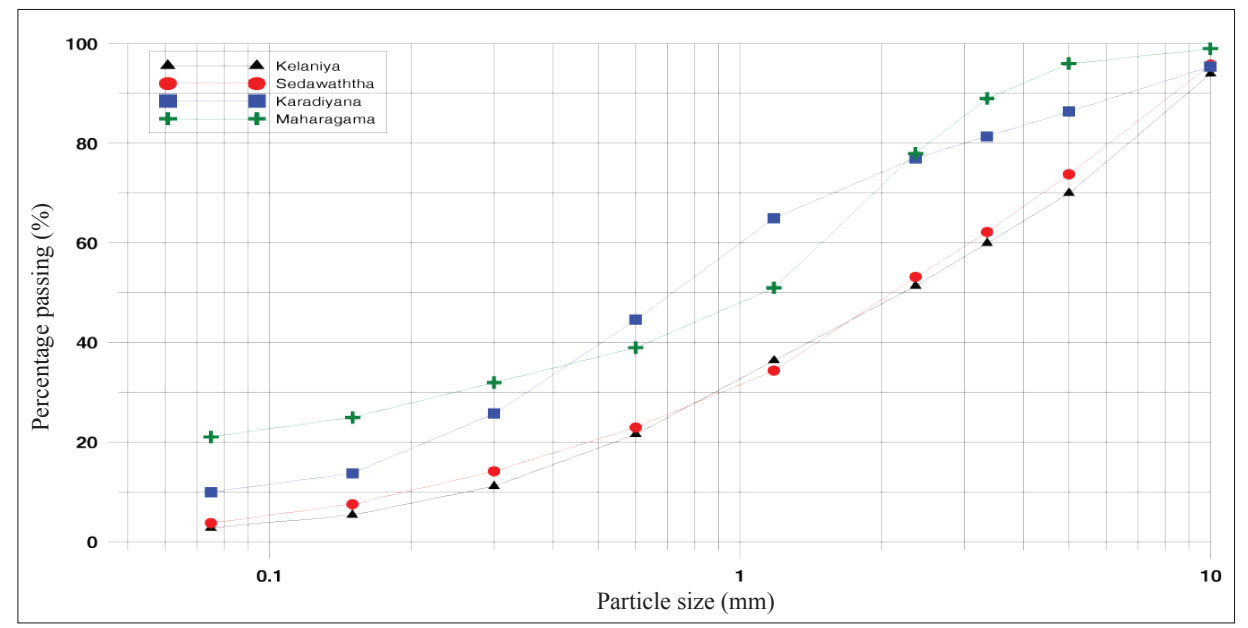

Figure 2: Particle size distribution of samples taken from dumping sites

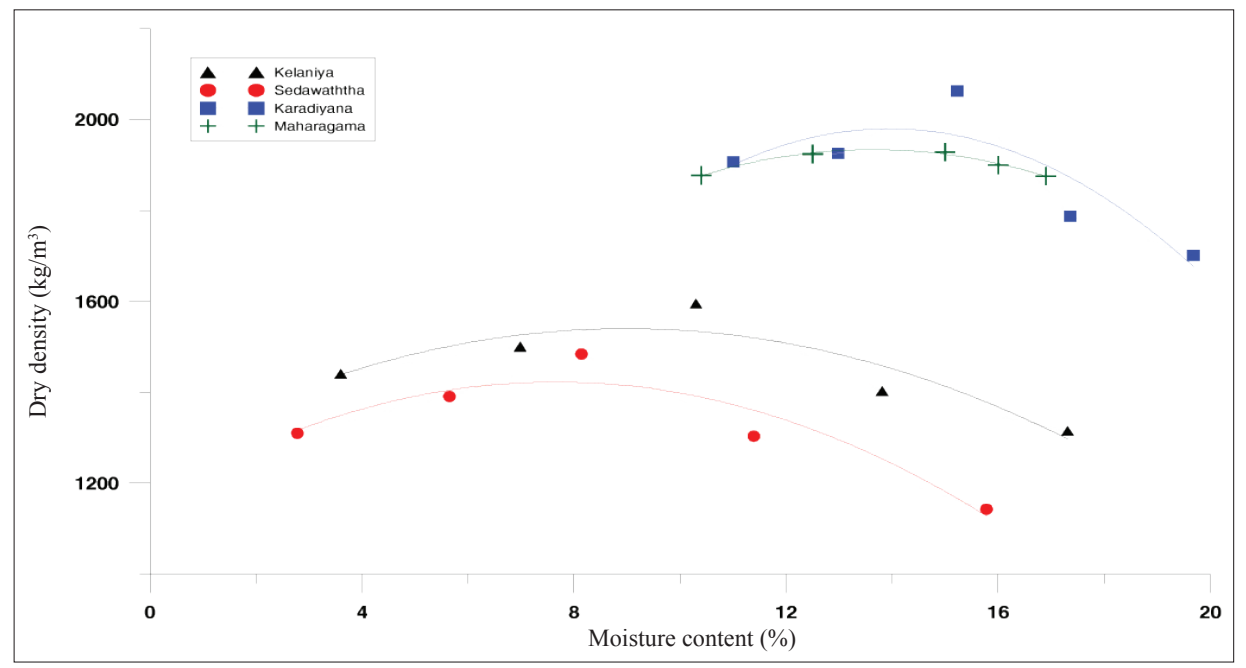

Figure 3: Standard proctor compaction curves for landfill sites 
Table 1: Atterberg limit results

\begin{tabular}{lccc}
\hline Location & $\begin{array}{c}\text { Plastic } \\
\text { limit (\%) }\end{array}$ & $\begin{array}{c}\text { Liquid } \\
\text { limit (\%) }\end{array}$ & $\begin{array}{c}\text { Plasticity } \\
\text { index (\%) }\end{array}$ \\
\hline Maharagama & 29 & 38 & 9 \\
Karadiyana & 15 & 24 & 9 \\
Kelaniya & 27 & 34 & 7 \\
Sedawaththa & 29 & 33 & 4 \\
\hline
\end{tabular}

been summarized in Table 1. The liquid limit values at Maharagama, Kelaniya and Sedawaththa were above $30 \%$ as required by the United States Environmental Protection Agency (USEPA) standards. The plasticity index of all the locations were below $15 \%$.

The results of sieve analysis and Atterberg limit test can be used to classify the soil type according to the unified soil classification system (USCS) and the

Table 2: USCS classification of cover soil

\begin{tabular}{lcl}
\hline Location & USCS classification & ASTM description \\
\hline Maharagama & SM & Silty sand with $<15 \%$ gravel \\
Karadiyana & SP-SM & Poorly graded sand with slit and $<15 \%$ gravel \\
Kelaniya & SP & Poorly graded sand with $>15 \%$ gravel \\
Sedawaththa & SP & Poorly graded sand with $>15 \%$ gravel \\
\hline
\end{tabular}

Table 3: Comparison of test results with guidelines for cover soil properties in landfills without gas collecting systems

\begin{tabular}{|c|c|c|c|c|}
\hline \multirow[t]{3}{*}{ Location } & \multirow{3}{*}{$\begin{array}{c}\text { Sieve analysis } \\
>30 \% \text { passed through } \\
\text { no. } 200 \text { sieve }\end{array}$} & \multicolumn{3}{|c|}{ Acceptability with EPA guidelines } \\
\hline & & \multicolumn{2}{|c|}{ Atterberg limit } & \multirow{2}{*}{$\begin{array}{c}\text { Proctor compaction } \\
\text { Dry density } \\
>1500 \mathrm{~kg} / \mathrm{m}^{3}\end{array}$} \\
\hline & & $\begin{array}{l}\text { Liquid limit } \\
\text { > } 30 \%\end{array}$ & $\begin{array}{c}\text { Plasticity index } \\
>15 \%\end{array}$ & \\
\hline Maharagama & Not acceptable & Acceptable & Not acceptable & Acceptable \\
\hline Karadiyana & Not acceptable & Not acceptable & Not acceptable & Acceptable \\
\hline Kelaniya & Not acceptable & Acceptable & Not acceptable & Acceptable \\
\hline Sedawaththa & Not acceptable & Acceptable & Not acceptable & Not acceptable \\
\hline
\end{tabular}

summary has been given in Table 2. The comparison of these results with the USEPA guidelines for cover soil properties in landfills without gas collecting systems (USEPA) are summarized in Table 3.

The gradation of soil is an important factor for compaction. Maharagama, Kelaniya and Karadiyana sites show a maximum dry density of more than 1500 $\mathrm{kg} / \mathrm{m}^{3}$, which is needed by the standards. Poorly graded soil does not compact well and thus, it enhances the soil gas transport parameters. It can be clearly seen that the Maharagama dumping site, which has a well graded grading curve has a low air permeability value compared to the other three locations (Table 4).

The air permeability $\left(K_{a}\right)$ values were calculated and tabulated (Table 4) to understand the gas diffusivity of the cover soil materials. While Maharagama and Karadiyana site materials have low air permeability values, the others have comparatively high values. The samples for this test were taken from the compaction test and the air permeability was measured at optimum moisture content to represent the worst possible situation.

In order to meet the required storage capacity of the soil cover, it should hold water until it is either transported through vegetation or evaporated through soil surface.

Table 4: Air permeability results

\begin{tabular}{lc}
\hline Site & $\begin{array}{c}\mathrm{K}_{\mathrm{a}} \text { at optimum moisture content and } \\
\text { maximum dry density }\left(\mu \mathrm{m}^{2}\right)\end{array}$ \\
\hline Maharagama & 30 \\
Karadiyana & 35.3 \\
Kelaniya & 40.4 \\
Sedawaththa & 45.4 \\
\hline
\end{tabular}




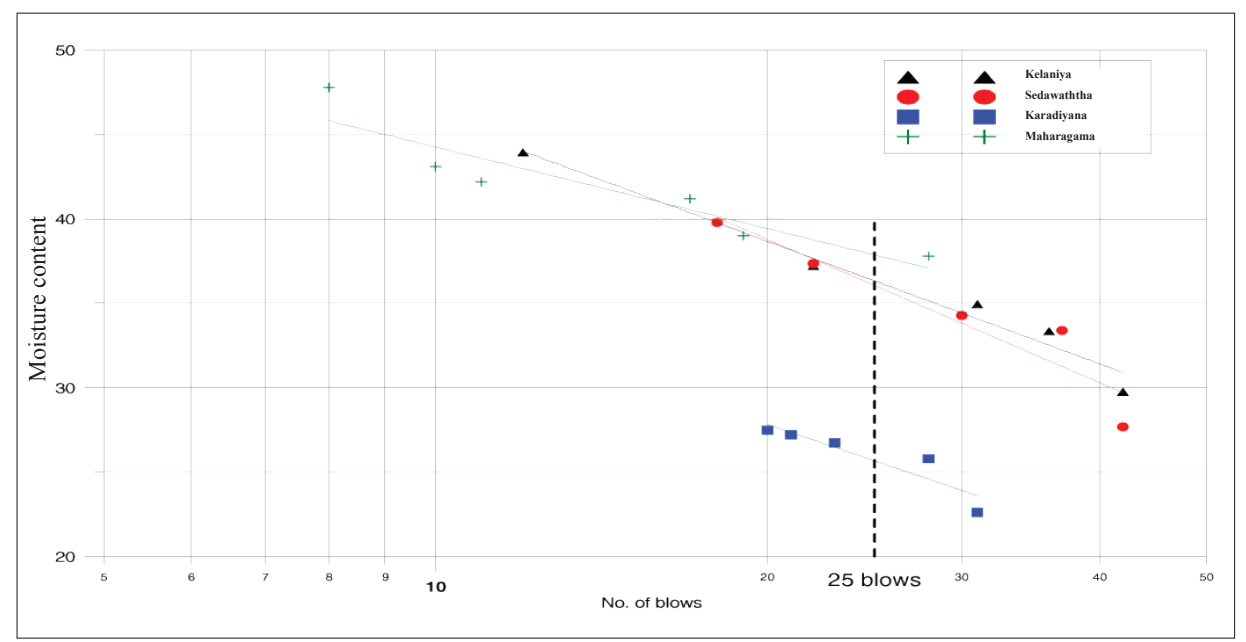

Figure 4: Liquid limit test results

Fine grained soils such as silts and clayey silts have a relatively high water retention capacity (USEPA, 2005). According to the USCS classification of the considered landfill cover soils (Table 2), Maharagama and Karadiyana covers consisted of a considerable amount of silt. A grass cover on top of the cover will enhance the water storage capacity and transpiration through vegetation (Hauser et al., 2001). For dump sites, which have a minimum water storage capacity, it is suggested to use a vegetative cover to minimize the infiltration of water.

The climate of the area should play a major role in designing a landfill cover. It is difficult to find a soil, which has high gas exchangeability and low water permeability due to the two opposite properties to be considered. Evapotranspiration covers are suitable for the Dry Zone due to low rainfall and long dry periods during the year. This type of cover should have high pore volumes in order to store water during the wet season and then get rid of the stored water through evaporation during the dry season. Landfill covers in the Wet Zone will need highly impermeable covers to keep out water, which in turn means that gas extraction systems will be required as the gas will get trapped inside (Ranasinghe et al., 2010). Since most cover soils are not up to the required standards stated in the USEPA guidelines, the majority of the landfill gas may be emitted through cracks and gaps in the cover or directly through the soil and not necessarily through the passive vents. Active or passive gas collection systems can be employed according to the standards (USEPA-600/R-05/123a) in order to collect the emitted gases. Based on the theoretical evaluations, welldesigned active collection systems could be considered as the most effective means of gas collection.

\section{CONCLUSION}

The major function of a cover soil is to reduce the quantity of water infiltration into the soil and control emission of pollutant gasses into the atmosphere. Since Sri Lankan dumping sites are not equipped with proper gas venting facilities, it is important to control these effects from the properties of cover soil. It is difficult to follow a guideline for final cover soil properties for Sri Lanka, as it is not directly stated by the authorities.

According to the United States Environmental Protection Agency (USEPA) standards for designing a final cover soil for low leachate production, at least $30 \%$ of the soil should pass through the no. 200 sieve and some silt as well. The plasticity index should not be less than $15 \%$ and the liquid limit should be over $30 \%$. The dry density should be over $1500 \mathrm{~kg} / \mathrm{m}^{3}$ at the optimum moisture content.

Considering the results of this study, it can be concluded that the landfill cover material at the Maharagama dumping site has an acceptable range in terms of reducing the greenhouse gas emissions. A dry density of more than $1500 \mathrm{~kg} / \mathrm{m}^{3}$ and proper gradation will reduce the quantity of water infiltration and thus reduce the amount of leachate generated by groundwater contamination. The presence of a considerable percentage of silt in this cover soil improves the water storage capacity and transpiration through vegetation.

At present, engineered landfills are an essential need for environmental safety and it is necessary to increase the awareness regarding environmental problems due to 
uncontrolled landfills. To reduce the risks due to operating uncontrolled landfills in Sri Lanka, gas collection pipes and proper vegetation covers must be introduced to minimize environmental risks. Existing dumpsites can be upgraded into sustainable landfills through a proper rehabilitation process (Centre for Environmental Studies, 2008). Since Sri Lanka has many open dumpsites, there must be a proper plan for rehabilitation of these sites.

\section{Acknowledgement}

Officials of the relevant Municipal/Urban Councils are acknowledged for providing the samples of cover soil for testing. The staff of the Geotechnical Laboratory at the University of Moratuwa are also gratefully acknowledged.

\section{REFERENCES}

1. Abichou T., Langoni G. \& Tawfiq K. (2003). Assessment of Alternative Earthen Final Covers for Florida Landfills. Report \#03-05. Florida Center for Solid and Hazardous Waste Management, University of Florida, USA.

2. ASTM (1998). Standard Test Method for Particle - size Analysis of Soil (D 422-63). ASTM International, West Conshohocken, USA.

3. ASTM (2010), Standard Test Methods for Liquid Limit, Plastic Limit, and Plasticity Index of Soils (D4318). ASTM International, West Conshohocken, USA.

4. ASTM (2012), Standard Test Methods for Laboratory Compaction Characteristics of Soil Using Standard Effort (12 $400 \mathrm{ft}$-lbf/ft3 (600 kN-m/m3) ((D698). ASTM International, West Conshohocken, USA.

5. Centre for Environmental Studies (2008). Dumpsite Rehabilitation Manual. Centre for Environmental Studies, Anna University, Chennai, India.

6. Hauser V.L., Weand B.L. \& Gill M.D. (2001). Natural covers for landfills and buried waste. Journal of Environmental Engineering 127(9): 768 - 775.

7. Iversen B.V., Schjonning P., Poulsen T.G. \& Moldrup P.
(2001). In situ, on-site and laboratory measurements of soil air permeability: boundary conditions and measurement scale. Journal of Soil Science 166(2): 97 - 106.

DOI: http://dx.doi.org/10.1097/00010694-200102000-00003

8. Liang P., Browser C.G. \& Bowen H.D. (1995). Finite element model to determine the shape factor for soil air permeability measurements. Transactions of the ASABE. 38(4): $997-1003$.

DOI: http://dx.doi.org/10.13031/2013.27878

9. Ranasinghe R.H.K., Nawagamuwa U.P., Wickramarachchi P.N.K. \& Kawamoto K. (2010). Gas exchangeable properties of "Maharagama" open dump cover soil. The Institution of Engineers Sri Lanka Transactions 1: part B. page numbers

10. United States Environmental Protection Agency (USEPA). Guidance for Design and Installation of Final Covers. Available at http://www.epa.gov/region6/6pd/pd-u-sw/ swguide.htm. Accessed on 08 December, 2011

11. United States Environmental Protection Agency (USEPA). Evapotranspiration Landfill Cover Systems Fact Sheet. Available at http://cluin.org/products/altcovers. Accessed September, 2013

12. United States Environmental Protection Agency (USEPA) (2005). Guidance for Evaluating Landfill Gas Emissions from Closed or Abandoned Facilities. (EPA-600/R05/123a).

13. Visvanathan C., Trankler J., Kuruparan P., Basnayake B.F.A., Chiemchaisri C., Kurian J. \& Gongming Z. (2005). Asian regional research programme on sustainable solid waste landfill management in Asia. Proceedings of Sardinia 2005, Tenth International Waste Management and Landfill Symposium, S. Margherita di Pula, Cagliari, Italy, 3 - 7 October. Environmental Sanitary Engineering Centre, Italy.

14. Weeks O.L., Mansell R.S. \& McCallister S.T. (1992). Evaluation of soil top-cover system to minimize infiltration into a sanitary landfill: a case study. Environmental Geology and Water Science 20(2): 139 - 151.

DOI: http://dx.doi.org/10.1007/BF01737880

15. Winkler W. (1999). Thickness of monolithic covers in arid and semi-arid climates. M.Sc. thesis, University of Wisconsin- Madison, Madison, USA. 